\title{
Quality of life, vulnerability and resilience: a qualitative study of the tsunami impact on the affected population of Sri Lanka
}

\author{
Alice Josephine Fauci, Manila Bonciani and Raniero Guerra \\ Ufficio Relazioni Esterne, Istituto Superiore di Sanità, Rome, Italy
}

\begin{abstract}
Aim. This qualitative study is aimed at analysing the impact of the 2004 tsunami on the Quality of Life of the Sri Lankan population. It focused on the factors that have contributed to an increase in the people's susceptibility to the impact of hazards - their vulnerability - as well as of the natural ability to cope of the populations affected - their resilience. Methodology. The study is based on the conduction of 10 Focus Group discussions and 18 In-depth Interviews, then analysed through a qualitative analysis software. Results and conclusions. The analysis shows that each factor involved in the interplay among the different processes that produced the changes in the affected people's quality of life is at the same time a damaged asset, a vulnerability factor and a resource to draw upon for coping. The complexity of this situation opens further speculation as to how disasters and relief interventions influence relationships and dynamics in society. This should thus be further investigated, together with the effects of individual and group trauma on society.
\end{abstract}

Key words: quality of life, vulnerability, resilience, qualitative research, disasters.

\begin{abstract}
Riassunto (Qualità della vita, vulnerabilità e resilienza: uno studio qualitativo dell'impatto dello tsunami sulla popolazione colpita dello Sri Lanka). Obiettivo. La presente ricerca qualitativa propone un'analisi dell'impatto dello tsunami del 2004 sulla qualità della vita della popolazione dello Sri Lanka, concentrandosi sui fattori che hanno contribuito ad aumentare, nella popolazione colpita, la suscettibilità ai disastri - la cosiddetta vulnerabilità - e la loro naturale capacità di recupero e ripresa - la cosiddetta resilienza. Metodologia. Lo studio ha previsto la conduzione di 10 Focus Group e 18 Interviste In Profondità. I dati sono stati poi analizzati con un software per l'analisi dei dati qualitativi. Risultati e conclusioni. Lo studio ha dimostrato che ognuno dei fattori presi in esame rappresenta allo stesso tempo un bene danneggiato, un elemento di vulnerabilità e una risorsa su cui fare affidamento per far fronte alle difficoltà e iniziare la ripresa. La complessità del quadro emerso apre il campo a ulteriori ipotesi su come i disastri e gli interventi di emergenza influenzino le relazioni e le dinamiche sociali, che andrebbero studiate ulteriormente, insieme agli effetti dei traumi individuali e sociali sulla società.
\end{abstract}

Parole chiave: qualità della vita, vulnerabilità, resilienza, ricerca qualitativa, disastri.

\section{INTRODUCTION}

The tsunami of 26 December 2004 hit Sri Lanka severely and caused an emotional wave across the whole of the world that channelled massive support to the affected areas. The tsunami had a huge human, physical, economic and social impact. The emergency phase was followed by the reconstruction and rehabilitation phase, where livelihood assets had a relevant role, in terms of capabilities, material and social resources, and activities that are required for a means of living. Moreover, beyond the personal and communal experiences of the disaster itself, a new dimension shaped life after the tsunami: the large-scale influx of aid and aid actors. The effects of foreign aid impacted on and permeated not only all levels of state and society, but also the recovery process itself.
Livelihood-centred approaches seek to gain an accurate understanding of people's strengths and how they endeavour to convert these into positive livelihood outcomes [1-3]. This requires a realistic understanding of all of these assets, to identify what opportunities they can offer, or where constraints may lie. Indeed, the significance of socio-economic factors in making people vulnerable to disaster is generally recognized, as well as the objectives of protecting and rebuilding livelihoods and communities after disasters, reducing vulnerability to future disasters, and making disaster preparedeness and prevention an integral part of development programmes [4]. However, whilst the livelihood approach incorporates shocks (such as natural disasters) as a highly significant component 
of the "vulnerability context", there have been few analyses of how these shocks affect livelihood assets and outcomes.

Although many assessment studies have been conducted by different national and international organisations to assess the impacts of this disaster and the later humanitarian response [5-12], no detailed information has been collected and elaborated regarding the social, economic and health status of the population in the aftermath of the tsunami.

Moreover, aside from its treatment in relation to development and empowerment, and to conflict perpetuation/ prevention, the influence of foreign aid in the recovery process has remained under-researched (see Bastian [13] for the first comprehensive study of the politics of foreign aid flowing into Sri Lanka). This influence includes such factors as access to the tsunami rehabilitation resources, presence of external actors, and displacement and resettlement movements.

The present qualitative study was part of a larger research project - which included also a Household Survey - that was financed through funds gathered for the South-East Seaquake Emergency and managed by the Italian Protezione Civile (The Italian Civil Protection Department) and that was implemented by the Istituto Superiore di Sanità (the Italian Institute of Health) in collaboration with the Sri Lankan Ministry of Healthcare, Nutrition and Uwa Wellassa Development. The project was aimed at the characterisation of the social, health and environmental risk at the community and individual levels in the affected and non-affected areas of the tsunami-affected Divisions of three selected Districts [14]. This main intervention was expected to provide information for the planning of support and rehabilitation activities that would pay overriding attention to the most vulnerable and marginalised of the people. Indeed, immediately after the conclusion of the project, the study's preliminary results were presented to the main stakeholders within a national conference in Sri Lanka, in order to support the priority setting of the ongoing planning of the recovery process. The commentaries and recommendations pointed out during the conference have been useful for finalising the study results and to strengthen the iterative analysis process of the qualitative data.

In this framework, the qualitative study was aimed at deepening the analysis of the impact of the tsunami on the population and their livelihood, by identifying factors of social, economic, physical and environmental vulnerability, and exploring the experiences of the population in the recovery process and their perceptions of the effectiveness of the relief interventions, along with their resilience and coping strategies. More specifically, the study focussed on three main aspects of their perception of the consequences of the disaster on their quality of life: their psycho-physical health (being); their sense of belonging to the community and of participation in the socio-economic life (belonging); and their expectations and projections for the future (becoming).

\section{STUDY CONCEPTS AND METHODOLOGY Study design and recruitment}

The qualitative study was based on focus group discussions (FGDs) and in-depth interviews (IDIs). The study design chose a purposive sampling to select the participants of 10 FGDs and 18 IDIs in the three Districts of Kalutara, Galle and Matara.

For each FGD, the aim was to obtain homogeneity within each group so as to capitalise on the shared experiences of the population. Thus, the composition of each FGD was characterised by the following variables: affected/ non-affected by the tsunami; beneficiary/ non-beneficiary of relief interventions; gender; ethnicity/ language; education level; age; religion; occupation; other variables.

For the IDIs, a set of different stakeholders were identified to deepen particular points of view. The key informants here were selected from the following categories and divided among the three Districts: people affected by the tsunami who were beneficiaries of relief interventions; people affected by the tsunami who were not beneficiaries of relief interventions; teachers (primary to ordinary level; Grades 1 to 8); local authority personnel (Grama Seveka); health personnel (Medical Officers); religious leaders.

\section{Study instruments}

A list of core questions that defined the areas to be covered was developed as the Questioning Route, according to the main topics identified as relevant for the study, such as the people's experience of the consequences of the tsunami, the people's perception of vulnerability, and the people's perception and experiences of recovery. These topics were investigated according to the conceptual framework adopted in this study: the quality of life and its three dimensions, being, belonging and becoming, as shown in Table 1 .

The FGD and IDI questioning routes drew upon semi-structured interviews consisting of open-ended questions that defined the areas and issues to be explored, according to the topics and the conceptual framework used. Once drafted, the study instruments were validated by Sri Lankan social scientists, to strengthen the validity and cultural appropriateness of the questions.

\section{Data collection and analysis}

A mixed team of national and international researchers implemented the qualitative research techniques in the selected areas. To ensure uniformity of data collection and to increase the quality of the study, the research team issued guidelines for conducting the FGDs and IDIs. These were conducted from February to July 2006 by trained Sri Lankan interviewers in the two local languages, Sinhala and Tamil, and in English by the ISS researchers, with the tape recordings tran- 
scribed in their respective languages. Afterwards, the Sinhala and Tamil transcripts were translated into English by professional translators. Quality control of the data was ensured through validation of transcripts and of transcript translations.

The FGDs and IDIs were analysed through qualitative analysis software (NUD*IST QSR, version 6). Drawing on the framework analysis approach [15], the analytical process involved the interconnected stages of: familiarisation through review and reading; identification of a thematic framework; indexing; charting; mapping and interpretation.

In the thematic analysis, the transcripts were coded and emergent themes were identified. This framework was then applied to the data (indexing) using textual codes (categories) to identify specific pieces of data that corresponded to the different themes identified. Further codes were then developed under each of the main themes, and the thematic framework was refined. Any disagreements among the researchers were resolved through discussion. The charting then was the results of the thematic analysis organised into these different themes by lifting quotes from their original context and re-arranging them under this appropriate newly developed thematic content, according to the conceptual framework of the study. In the final stage, the mapping process allowed the visual display of the concepts, ideas, associations and relationships that emerged from the data, and the development and testing of the interpretations.

Table 1 | The three dimensions of Quality of Life

\begin{tabular}{|c|c|c|}
\hline Life domains & Sub-domains & Consideration \\
\hline \multirow[t]{3}{*}{ Being } & Physical being & $\begin{array}{l}\text { Physical well-being/ } \\
\text { appearance }\end{array}$ \\
\hline & $\begin{array}{l}\text { Psychological } \\
\text { being }\end{array}$ & $\begin{array}{l}\text { Psychological health/ } \\
\text { adjustment }\end{array}$ \\
\hline & Spiritual being & $\begin{array}{l}\text { Personal values, } \\
\text { conduct and spiritual beliefs }\end{array}$ \\
\hline \multirow[t]{3}{*}{ Belonging } & $\begin{array}{l}\text { Physical } \\
\text { belonging }\end{array}$ & $\begin{array}{l}\text { Connections with physical } \\
\text { environment }\end{array}$ \\
\hline & Social belonging & $\begin{array}{l}\text { Connections with the social } \\
\text { environment and the sense } \\
\text { of acceptance }\end{array}$ \\
\hline & $\begin{array}{l}\text { Community } \\
\text { belonging }\end{array}$ & $\begin{array}{l}\text { Access to resources } \\
\text { are normally available to } \\
\text { community members }\end{array}$ \\
\hline \multirow[t]{3}{*}{ Becoming } & $\begin{array}{l}\text { Practical } \\
\text { becoming }\end{array}$ & Day-to-day actions \\
\hline & Leisure becoming & $\begin{array}{l}\text { Relaxation and stress } \\
\text { reduction }\end{array}$ \\
\hline & Growth becoming & $\begin{array}{l}\text { Improvement/ maintenance } \\
\text { of knowledge/ skills }\end{array}$ \\
\hline Modified from & & \\
\hline
\end{tabular}

\section{Main study concepts}

The main concept characterising the research is that of quality of life, which includes both the components and determinants of health and wellbeing, developed on the basis of an analysis of the literature, and drawing upon a conceptual model that is consistent with recent definitions of health and health promotion [16]. Through its three dimensions of being, belonging and becoming, it emphasises the physical, psychological and spiritual functioning of the individual, their connections with the physical, social and economic environment, and the opportunities for maintaining and enhancing their skills.

In social sciences, the concept of disaster is aimed at identifying the social aspects rather than its physical determinants, and it allows the opportunity to study human behaviour in which adaptation, resilience and innovation are often more clearly revealed than in "normal" and stable times [17-19].

Finally the concept of vulnerability, which includes an external and internal sides [20], here refers to the structural situation of a socio-system, not to its degree of exposure to risk agents and resilience, considered as responsiveness in exploiting opportunities and in resisting or recovering from the negative effects of the changing environment.

\section{RESULTS}

The thematic framework that was developed based on the objectives of the study and the narratives of the participants included their perceptions and opinions according to two main categories: (i) the consequences of the tsunami; and (ii) the recovery process, as shown in Table 2.

The emergent themes are here presented according to the conceptual framework that draws upon the definitions of quality of life and vulnerability, as being, belonging and becoming, and focussing on change. Key citations are included to support the emergent themes, with details indicating the participant characteristics: (tsunami affected/ non-affected - beneficiary/ non-beneficiary - gender - ethnicity/ language - education level - district).

\section{Being}

"When talking about the changes after the tsunami, even the dress I am wearing now is what I got due to tsunami. We are not what we were before" (affected - beneficiary - male - Tamil - low - Galle).

The being dimension of quality of life refers to perceptions of one's own psycho-physical status, which are presented here according to three categories, or textual codes: degree/ extent of damage; psychological and physical health; and human capital, which includes feelings/ emotions and skill/ ability to work.

For the degree/ extent of damage, the data analysis suggests that the devastation provoked by the tsunami was massive: 


\begin{tabular}{|c|c|c|}
\hline Main categories & Sub-categories & Sub-codes \\
\hline \multirow{4}{*}{$\begin{array}{l}\text { Perceptions and opinions of the } \\
\text { consequences of the tsunami }\end{array}$} & Damage & $\begin{array}{l}\text { Degree } \\
\text { Extent }\end{array}$ \\
\hline & Type of damage & $\begin{array}{l}\text { Housing } \\
\text { Health } \\
\text { Income-generating activities } \\
\text { Personal and household belongings } \\
\text { Family composition } \\
\text { Infrastructures }\end{array}$ \\
\hline & Quality of life and well-being & $\begin{array}{l}\text { Human capital } \\
\text { Social capital } \\
\text { Financial capital } \\
\text { Political capital } \\
\text { Natural capital }\end{array}$ \\
\hline & Vulnerability & $\begin{array}{l}\text { Physical } \\
\text { Social } \\
\text { Economic } \\
\text { Environmental }\end{array}$ \\
\hline $\begin{array}{l}\text { Descriptions, perceptions } \\
\text { and opinions of the } \\
\text { recovery process }\end{array}$ & $\begin{array}{l}\text { Type of relief intervention } \\
\text { Type of donor } \\
\text { Effectiveness } \\
\text { Degree of recovery } \\
\text { Obstacles to recovery } \\
\text { Resources and coping strategies } \\
\text { Requests, hopes and expectations }\end{array}$ & \\
\hline
\end{tabular}

"Now we think... that actually we have nothing more to loose. We have fallen right down (...). It is a big blow. What happened was total destruction" (affected - beneficiary - male - Tamil - low - Galle).

The loss of assets and outputs, and the damage to property, environment and economy were considerable, with serious consequences for the people affected. Regardless of their initial status, they experienced a drop in their socio-economic level, with negative consequences on their livelihood and on their sincere efforts to re-build their lives.

There was also a profound impact on people not directly affected by the tsunami. They suffered many indirect effects to varying extents and for different reasons, such as lack of medical facilities, food, medical supplies, electricity, and safe water supplies.

While no big consequences emerged with reference to physical health (problems only referred to scratches, wounds and injuries, or worries about the spreading of infection and epidemics), the tsunami had a tremendous impact on the psychological health of the people. Indeed, all participants indicated that people still lived with fear, worries and profound grief and sorrow, while sometimes expressing how they themselves continued to suffer psychologically as a result of the tsunami. People were traumatised by the tsunami events they had experienced, with many reports of sleeping disorders, fear of the sea, and children not going to school because of continuing fears and distress.

One of the main consequences of the impact of the tsunami on human capital is linked to the psychological trauma, to the mental, psychological and physical ability to work:

"I am a teacher by profession. Teaching needs a good mental strength. My mental courage and moral is totally lost. I do not think we can get that confidence back... For us, these teaching professions... have a lot of experiences. But to start newly... It is difficult to build up our minds. Creativeness lessened considerably. That is a great loss of skills from my point of view" (affected - beneficiary - male - Sinhala - high - Matara).

The major concern relating to the feelings and emotions expressed by the key informants was their fear that emerged after the tsunami, in terms of their safety, as they were afraid that another tsunami could strike. This fear has consequences on the well-being of the people, and on their choices and style of life. Even the people who were not immediately exposed to the tsunami have developed fears about a potential reoccurrence. This shows that the disaster shocked the whole population, as a consequence of a natural phenomenon that completely surpassed the people's imagination:

"In the night I keep awake watching the sea" (affected - non-beneficiary - male - Tamil - low - Kalutara). 
When considering physical vulnerability, concerns over security emerged as a major issue during both the tsunami response and the recovery phases, with worries about women's security and problems inherent to displacement still persisting. Here, in general, the main worries expressed by both men and women were related to the well-being and education of their children.

In terms of time, except for the dangers and precariousness of fishing, there were no specific expressions of fear and worries relating to the past, before the tsunami; the fears were always related to the emergency period, the present and the future. Indeed, when asked directly about environmental vulnerability, it emerged that there was absolutely no perception of risk before the tsunami.

The expression of feelings of frustration was also frequent, as a condition of being dependent on the help of others, and to their loss of confidence. In contrast, there also emerged feelings of pride and determination among the affected population, with expressions of satisfaction about the way they were facing their difficult situation, along with criticism of others, for lack of initiative and reluctance to take up their life. Here, willpower emerged as a significant resource to draw upon: very resolute and determined people resorted to different expedients to cope with the difficult situation, such as doing odd jobs and additional jobs, changing job, or simply working more. Knowledge and skills were often recognised as being fundamental to the ability to recover. Fishermen had to find new ways for catching fish. Women also started new jobs or income-generating activities:

"I will say really it's my own effort. I saved from my husbands earning and with that money I repaired the house and bought all the necessary items" (affected - beneficiary - female - Sinhala - low - Kalutara).

A further important theme that emerged was the role that religion had in the affected areas: following the tsunami, people sought shelter in temples, mosques and kovils (temples), and received help and assistance from the local community through their religious leaders. At the same time, there were many allegations of favouritism and bias made by different key informants, who frequently expressed the feeling that during the relief work there had occurred injustices and discrimination. However, while the Sinhalese mentioned this without attributing them to ethnic or social factors, the Tamil-speaking people (both Muslim and Hindu) indicated ethnic discrimination, which was explicitly denied by the Sinhalese in certain cases.

According to several key informants, the tsunami and the aid that arrived afterwards made the people become selfish and show greed. This was generally considered as one of the major changes in the human qualities of the people:

"There were people like that, opportunists. Now say, if five boats are to be given, one person tries to grab all five boats, they don't think that the others also should be given... They are greedy... the people became selfish... people have changed. Those are the people who came to temple daily; attended church daily. They have lost the human values" (affected - beneficiary - male - Sinhala - Galle).

\section{Belonging}

"Normally in our area everyone helped others when they are in need. After the tsunami this relationship became stronger. Habit of helping others increased" (non-affected - female - Sinhala/Tamil - high - Kalutara).

"The bond we had in our village was broken. The social attachments eroded gradually" (affected non-beneficiary - male - Sinhala - low - Matara).

The belonging dimension of the quality of life refers to perceptions of the sense of belonging to the community and of participation in the socioeconomic life. This includes the themes emerging from the categories of social, financial, political and natural capital.

For social relationships and networks, while after the tsunami some felt that relationships within family and community remained the same, in general, a change in social relations and networks was recognised. These were sometimes positive, both in resettlement areas, where the people were starting to integrate themselves within the new communities, and in affected areas, where the tsunami had contributed to the strengthening of bonds within families and communities. Some experienced negative changes as a consequence of the tsunami, feeling alienated and less integrated within the community.

There was also a negative impact on social relations due to the physical separation of the people, who had to move to other places or who had lost their previous living and/or working environments. In addition to this loss of social support and social relations, these problems meant that those affected by the tsunami also experienced a loss of social recognition of their status:

"The society looked down on us when our financial position was getting diminished... Even now we are on a very low level. The social attachments eroded gradually. The recognition in society becomes less when there is no money... When unable to settle the debts, that man's social standard falls completely" (affected - non-beneficairy - male - Sinhala - low - Matara)

For trust and solidarity among the populations, the general opinion was that initial aid was provided to victims irrespective of ethnicity, caste or religion, which created a certain level of solidarity and generosity.

However, opinions about the situation during the recovery period diverged. Although some thought that the unity within the communities had remained the same or had increased as a consequence of the tsunami, others pointed out critically that the tsunami has undermined the mutual trust and solidarity. Here again, it is worth stressing that in accounting 
for the lack of solidarity, the ethnic factor was raised as a major cause by the Tamil-speaking people:

"Here no unity, only problems... During tsunami time, from people of the church they have shared the clothes and food items. You know what that Sinhala fellow did? He took all the good items and gave back the balance to others that dresses no one can wear. But all our Muslim people gave the items to Sinhalese. They didn't bother about us or about our children" (affected - non-beneficiary - female - Tamil - Kalutara).

In general, increases in social conflict within communities was linked to the aid and relief work conducted after the tsunami. Where there was no increase in conflict or violence compared to the past, this was attributed to a lack of changes within the community after the tsunami.

For the financial capital, in general, even if pretsunami employment and livelihood pursuits have been taken up again, the revenue is sometimes lower due to missing equipment, use of damaged equipment, and marketing problems.

As one of the primary economic activities along the coast, fishing was paralysed for several months after the tsunami by two main factors: destruction of and damage to boats and fishing equipment, and collapse in the market, since people refused to eat fish. This affected the livelihood not only of those fishermen who had lost their boats and equipment, but also of all of the people working in the fishery industry.

The same difficulties had to be faced by fish sellers, who lost their working opportunities, especially during the first months after the tsunami, and who also represent a very vulnerable category.

For the people working in the other main productive sector, tourism, their loss of employment, insufficient earning opportunities, and their consequent economic problems emerged as key factors affecting their livelihood. The loss of houses and other assets for people engaged in other economic activities, such as production equipment and goods for agriculture-related jobs and artisan and cottage industries, also had serious effects on their livelihood. The situation was even more critical for casual workers and labourers, whereby lack of equipment and precariousness of work were indicated as being the major obstacles towards recovery, although the lack of money was referred to most frequently.

The affected people also lost their savings during the tsunami, since the water washed away money and cheque books kept at home, which contributed further to the weakening of their financial strength. This financial weakness of the affected people made it more difficult for them to obtain credit from banks and other providers, a difficulty that increased with the passing of time. The possibility to obtain credit and loans from relatives, friends, banks or other organisations emerged as a key factor in the start-up of the recovery process. This was particularly true for several women who started additional income- generating activities through loans obtained. For the poorest, credit and borrowed money was the only resource to eke out a survival. At the same time, many affected families had to turn to their relatives for help, with the local community also proving to be an important resource.

Therefore, the tsunami had a devastating effect on the livelihood of people of all sectors of employment and economic activities:

"After tsunami it is like both legs of each family is broken. There they need crutches to rise again. If not two, at least one is needed for them to take a step" (affected - beneficiary - male - Tamil - low - Galle).

Claims and assets are rights that are politically defended and how people access these assets depends on their political capital. The analysis suggests that in general, no changes emerged for the affected people after the tsunami with reference to the level of political capital, although there emerged their weakness in relation to their ability to access policy-making decisions, with particular reference to policies of the buffer zones and the boundaries between affected and non-affected areas. The importance of political capital as an asset was demonstrated by the way in which contacts and links with public officials and politicians emerged as a key element for receiving aid:

"After the tsunami, people got many things done by claiming that homes were destroyed. Those were false claims but with the help of politicians they got things done" (affected - beneficiary - female - Sinhala - Matara).

With reference to natural capital, most of the environment-related problems referred to the immediate post-tsunami period, when the need for clean drinking water and water for washing was a high priority because of the high levels of salinity in the ground water. However, as with other environmental-related problems, water-related problems still persisted during the recovery period.

Regarding exposure to future natural, weather-related and climate-related hazards, the vulnerabilities and risks affecting some of the study communities include droughts and floods. However, with most of the people still living on exposed coasts, the main risk perceived in these areas is as indicated above: the fear of another tsunami. Finally, environmental hazards will also come from the degradation of the environment due to the impact of the tsunami on the land and soil.

\section{Becoming}

"We do not know of our future, it is God's Will. We have gone behind 10 years in progress" (affected - non-beneficiary - male - Tamil - low - Kalutara).

As the becoming dimension of the quality of life refers to perceptions of expectations and their projection into the future, this includes themes emerging from the categories of: degree of recovery, tsunami response, and requests, hopes and expectations. To 
understand the becoming dimension, however, an analysis of the perception of the tsunami impact and of the recovery process itself is needed.

Key-informants reported different perceptions and experiences of their degree of recovery, with the full range of all possibilities seen. Therefore, some people stated that they had not recovered at all after the tsunami, while a few people considered that they had done. In our understanding of the reasons why some have recovered better than others, it is generally recognised that the disaster had different effects according to the different situations; therefore, the level of a person's recovery depended essentially on their former socio-economic status, the degree and type of damage, the kind of help they received, and their skills and willpower. In general, however, regardless of their socio-economic characteristics and the type of damage, the majority of the affected people considered themselves to not have recovered yet when they compared the changes in their present situation as compared to the past.

As for the tsunami response, the rescue services and immediate relief were provided to the tsunami victims through a variety of actors. These included the government, national and international NGOs, religious associations and institutions, and people's own initiatives. The key informants generally described these operations as effective in terms of both the results and the processes involved. There were also spontaneous initiatives that provided help, such as relatives living abroad or outside the affected areas who provided financial help.

Although the judgement was, on the whole, positive, some criticisms emerged with reference to the work of the government, and its attitude and performance, vis-à-vis the beneficiary population. In general, however, pitfalls in the effectiveness of the immediate relief interventions were not ascribed to the type of donor, but to difficulties and shortcomings intrinsic to the relief operations themselves.

Other factors of vulnerability can be identified by analysing what key informants referred to as the major obstacles to their recovery, aside from the above-mentioned economic issues. Bureaucratic issues, such as a lack of requested documents or the management of relief intervention by local authorities, were indicated as major obstacles for recovery of the affected people. Indeed, the analysis suggests that people's vulnerability was closely linked to the ownership of their assets and entitlements: the less assets and entitlements a person had, the more vulnerable they were.

Failure in getting aid and assistance was often indicated as a pitfall in the recovery process. Indeed, as already mentioned, the ability of people to re-establish their lives and to support each other appears to have been adversely affected by the tight control held by certain groups and individuals within communities over the distribution of relief supplies, as well as by bad management of the relief interventions. Injustice and inequality in aid distribution was often given as the major obstacle to recovery, thus emerging as an additional factor in their vulnerability. Here again, in accounting for such injustices, the ethnic factor was raised as a major cause by the Tamil-speaking people, while the Sinhalese indicated other reasons, which basically arose from private relationships.

The analysis suggests, however, that the recipient population perceived the aid in a highly critical manner. This had to do with the evidence of differential patterns of distribution and the instances of neglect and delay, as emerged from the assertions of aid maldistribution, allegations of favouritism, feelings of suspicion, and accusations of exclusion and partiality:

"That distribution was not fair. Some people received those that they deserved. But there were people who didn't receive anything. The able people got most of the things" (teacher - female - Sinhala - Galle).

Similarly, there were problems of dishonesty arising from those who took advantage of the aid through false declarations. Indeed, for the problems of inequity and unfairness in the delivery of relief services, the responsibility was attributed also to the greed of the people themselves, as emerged from several accusations of abuse of the situation for people's own benefit, as mentioned above.

The geographic separation that defined the areas "hit" and those not considered to have been hit, which were thus excluded from aid, did not appear to be just. Indeed, the separation between those with rights to aid and those without was considered to be relatively arbitrary. This was complained about by the affected, non-beneficiary people on a number of occasions, who pointed out that the interventions did not involve the population that lived outside of the areas identified as being hit, even if they had also suffered damage.

Here there were also critical reports mainly on the part of the Tamil-speaking people, who again indicated ethnic discrimination.

When analysing people's requests and hopes for the future, it is evident that the major expectation was indeed for an improvement in their economic situation and the reaching of their former social status. To improve their economic livelihood, there were a number of major requests of the tsunami-affected people. The first of these was the continuing need for economic help, in the form of money. This also encompassed the need for production equipment and, more indirectly, included general requests for help:

"Because we have now fallen down, somebody will have to give us a hand to lift us at least one step up. If we are lifted one step up, then we will be able to go up another step" (affected - beneficiary - male - Tamil - low - Galle).

There was also recognition of the importance of practical training, for the improvement of skills and knowledge, which could then lead to self-empowerment, as the ability for improvement without external aid.

The major concerns for the future were still about housing. This emerged not only with those who had 
lost their homes and were still waiting, but also for people who were resettled in other places, and for those who remained were they were and now feel unsafe or in an environment that did not fit their social and cultural requirements:

"Because I went to very far place and they told me like it's going to be very difficult for me to bring up my children in a way that's correct. Now how can I bring up my children in a different environment? Here of course school is near by; in that new place we won't have Madarasas. We have to think about our religion also" (affected - non-beneficiary - female - Tamil - Kalutara).

Finally, with the major expectation for the immediate future of some of the people relating to correct management of the relief work, the education of the children also emerged as a major concern.

The emergent themes presented here are graphically represented in Figure 1.

\section{DISCUSSION}

This study shows that regardless of their initial socio-economic status, the tsunami impact was experienced by most of the affected people as total damage, which signifies the extent of the consequences on their life, as a metaphor for the losses suffered, in terms of human, social, financial, political and natural capital. Indeed, as reported by several studies conducted on the tsunami impact on psychological health and wellbeing, this natural disaster aroused one of the most abrupt and widespread loss of place and loss of livelihood incidents ever recorded [7, 21].

In line with relevant reviews indicating that disasters have psychopathological consequences besides medical and social ones [22, 23], this study indicates that the trauma provoked by the tsunami had a very profound impact on both affected and not directly affected people. Communities, families and children "internalised" many of the fears and anxieties linked to the loss of family and homes, suggesting the need to consider and study further the "contagious" effects of trauma caused by such natural disasters [21, $24,25]$. As shown by a study on collective trauma in northen Sri Lanka, exposure to conflict, war and disaster situations impacts on fundamental family and community dynamics, which results in changes at a collective level [26]. Recent studis have also highlighted in particular the effects on children [27] and the need for targeted specialized interventions for children suffering from post-traumatic stress disorder [28, 29].

The analysis also indicates the importance of social support coming from family and friends, or from a wider social network, as a resource that can be drawn upon to cope with trauma or economic disruption. In the literature, it is generally recognised that social support is the individual's perception of the support given (or the psychological experience of the helpfulness of others), rather than some objective or observable phenomenon [30]. However, the study shows how the ready availability of a clear support system can be a variable that makes the difference with reference to the natural resilience and ability to cope in such populations affected by disasters. This is also supported by a recent study indicating the need for financial donors to relax requirements, while concentrating on credit discipline [31].

On the other side, (mis)management of the relief intervention by local authorities, and injustice and inequality in aid distribution were often referred to as major obstacles to recovery, thus emerging as an additional factor of vulnerability. Similar concerns have been expressed in other recent studies, indicating that competition, housing anxiety and bufferzone implementation have resulted in obstacles to equitable rebuilding of houses and livelihoods [32], as well as the need for further beneficiary and lo-
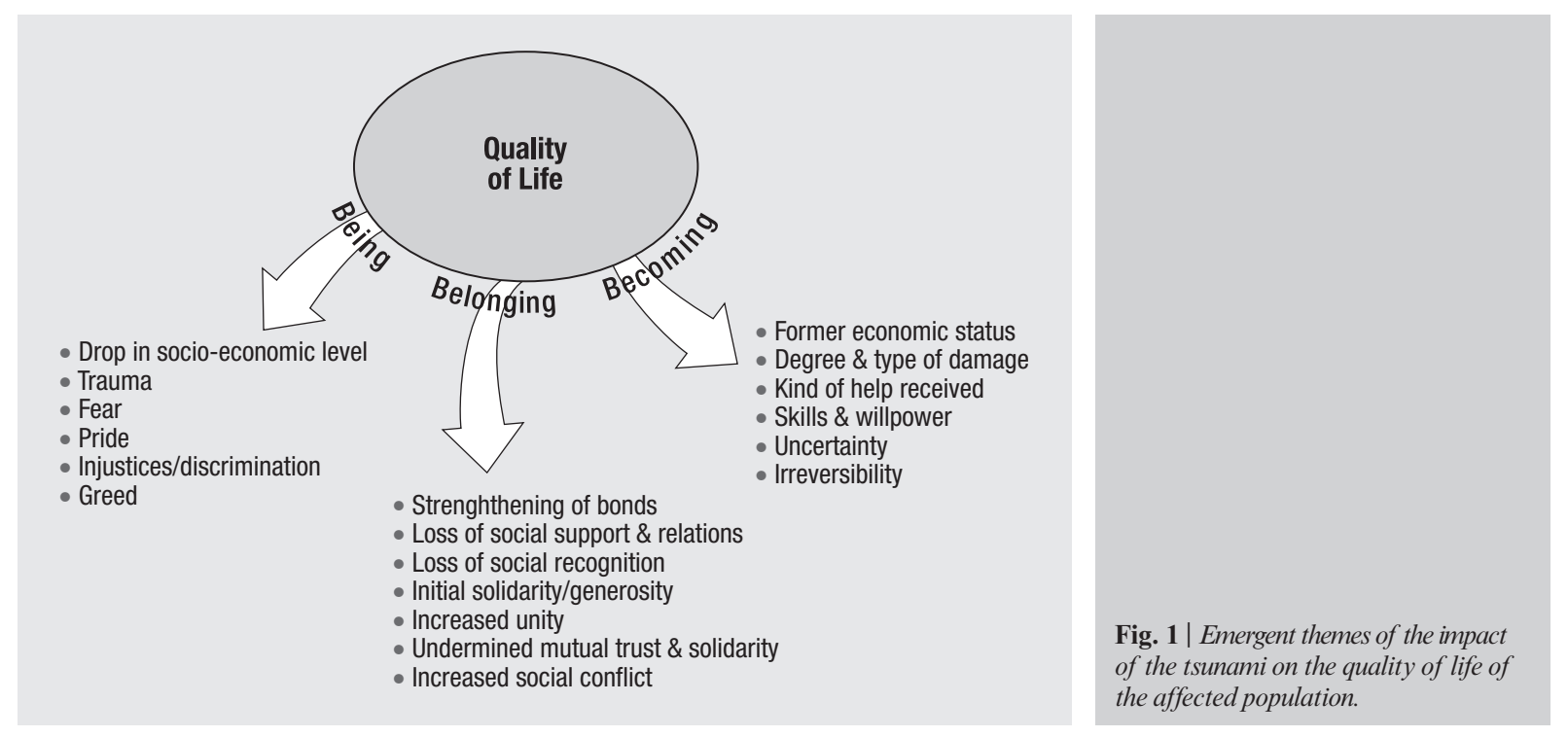
cal-network feedback in disaster planning [33, 34], and the need for specific interventions to address the health inequalities that internally displaced peole living in transitional camps reported [35].

However, the present study indicated that while the Sinhalese mentioned injustices and accounted for them in terms of corruption or preferential treatment, both the Muslim and Hindu Tamil-speaking people pointed to ethnic discrimination, which they also invoked for the lack of solidarity.

As argued in a study on vulnerability, social exclusion and conflict in Sri Lanka:

"A person's ethnic consciousness may be seen as a lens through which a person tries to comprehend his defencelessness within a given socio-economic environment and in time develop some coping mechanisms against perceived threats" [36].

Consistent with this argument, the present study noted that Tamil-speaking people often used the ethnicity framework for understanding vulnerability and coping, since the "ethnic other" is often perceived as the primary source of vulnerability, while one's own ethnic group is identified as an important means of coping.

The responsibility of the instances of unfairness was also attributed to the greed of the people themselves, which was generally considered to be linked to the dynamics put into action by the aid and relief work, which made the people become selfish. This suggests that it is wrong to claim that the tsunami had a uniformly impoverishing impact on all of the affected population; instead we must recall a concept developed in studies on conflict and war, the so-called "greed aspect of the war", which indicates the role of "conflict entrepreneurs" within a "war economy" [36]. Similarly, the present study indicates that there was a "greed aspect of the tsunami" that can contribute to the perpetuation of poverty trends within such communities hit by disasters.

Although the tsunami affected the lives of almost everyone who lived in the coastal areas that were hit, irrespective of ethnic identity, status and income level, our analysis indicates that its devastating effects were more severe on the poorer and more vulnerable sections of the population, such as the fishermen and the fish sellers, who were already highly vulnerable due to the precarious and dangerous nature of their job and their low level of income. Here, the very possibility of continuing the job was dependent on the possibility of borrowing money or working equipment. As pointed out by a study on the tsunami effects on fisheries and coastal livelihood [37], knowledge and skills, together with access to resources and facilities, have a significant influence on the capacity building of livelihood assets.

Whilst the devastating event of the tsunami revealed the enormous, yet totally unappreciated, vulnerability of the coastal communities in Sri Lanka, this and other vulnerability studies following the 2004 tsunami [38-40], indicate that special vulnerability to sea-related disasters had not been perceived before. As argued by Birkmann \& Fernando [38], societies need to measure their vulnerabilities in advance, and to make adequate provision. To do so, they have to understand the complex relationships between natural hazards and the related social, economic and environmental vulnerabilities.

As argued by Bird and Dominey-Howes [41], effective responses to tsunami warnings are highly dependent on the public awareness and perception of the tsunami hazard and risk. At present, no efforts have been made to investigate and analyse the public awareness of tsunami hazard and risk, and as such, emergency managers have little idea of the likely challenges that can arise during appropriate tsunami risk management.

If recognising and measuring vulnerabilities is thus the first step towards disaster-resilient societies, it is, however, just one side of how people take risk-related decisions. As pointed out by Heijmans [42], grassroot communities do not use the concept "vulnerability"; they approach recurrent "adverse events" as part of their "normal life", while rare and new disasters, such as a tsunami, are dealt with from a perspective of survival. Vulnerability to disasters is thus a matter of perception, but the view of local people is lacking in the perceptions of most aid agencies. It is therefore important to give affected communities a voice, to recognise their risk perception as well as their active role in exploring strategies to address the root causes of their vulnerability.

Overall, analysis of the factors that contributed to an increase in the people's susceptibility to the impact of hazards, their so-called vulnerability, as well as of the natural ability to cope by the populations affected, their so-called resilience, shows that each of the factors involved in the interplay among the different processes that produced the changes in their quality of life are at the same time a damaged asset, a vulnerability factor and a resource to draw upon for coping.

The conceptual map that has emerged from the data analysis here is illustrated in Figure 2. This represents the Tsunami Story, namely people's perceptions of the impact of the tsunami on their quality of life and their experience of the recovery process, as has emerged from their own accounts.

The perceived changes in the three domains of the Quality of Life (being, belonging, becoming) are influenced by the tsunami impact on the one hand, and the recovery process on the other. These are, in turn, affected by interactions between the two opposite forces: the vulnerability factors, which have increased people's susceptibility to the impact of hazards and disasters, and the resilience factors, which have increased people's ability to cope.

Newton's second law of motion, which states that a body of mass subject to a force undergoes an acceleration that has the same direction as the force and a magnitude that is directly proportional to the force and inversely proportional to the mass, provides our interpretative key of the conceptual map we propose. For 

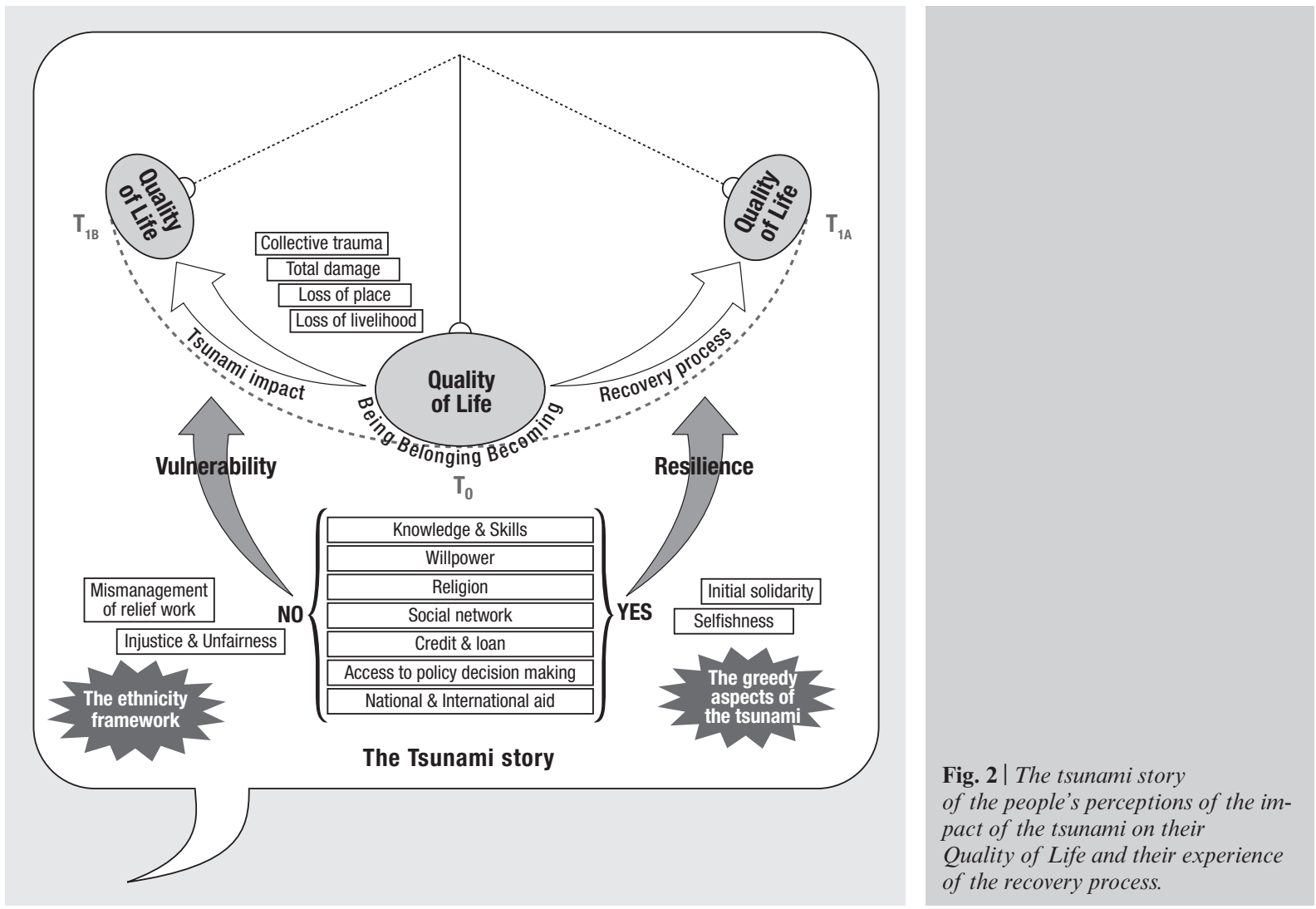

this key, Quality of Life is represented as a pendulum that oscillates within a temporal axis from the point given as $\mathrm{T}_{0}$ in Figure 2, which represents the quality of life of those who suffered damage in the immediate moments following the tsunami. During the recovery phase, through their resilience, the people affected can undergo quality-of-life improvements, hypothetically returning to their previous pre-tsunami situation, or better, taking them to $\mathrm{T}_{1 \mathrm{~A}}$; or through their vulnerability they can undergo quality of life deterioration, tending towards $T_{1 \mathrm{~B}}$. The overall effects will thus depend on the actions/ interactions of these two opposing vectorial forces of variable strengths that are represented as these factors of vulnerability and resilience, thus forming the Pendulum of the Quality of Life.

The metaphor of the Pendulum of the Quality of Life as the interpretative key of the conceptual map has indeed a mere explicatory function: it is provided in order to facilitate the reading of the map itself and it is not intended to represent the application of physics principles to social science. Notwithstanding, if we consider the two opposing vectorial forces of the macro-system represented in the map (vulnerability and resilience) - irrespective of the contingent individual elements which compose them - we cannot exclude that in a certain situation the phenomena described may repeats itself identically. In this sense, the representation provided within the framework of the Newtonian law appears to be coherent, without stating in any way the applicability of the Newtonian mechanics to the situation studied, nor the validity of a qualitative study through the use a physics formula.

The complexity of this situation can but open further speculation as to how disasters and relief interventions influence relationships and dynamics in society. This should thus be further investigated, together with the effects of individual and group trauma on society. As argued by De Mel, McKenzie \& Woodruff [43], socioeconomic factors are not significant in predicting the dynamics of mental health recovery, since mental health recovery from a given initial level appears to depend largely on time since the disaster, and not on economic recovery of an individual's livelihood.

\section{CONCLUSIONS}

The analysis of the factors increasing the vulnerability and/ or resilience of populations affected, shows on one hand that as with any natural disaster, the tsunami exacerbated any previous socio-economic or psychosocial problems that people had, as well as prompting new ones, and on the other hand, that the natural resilience and ability to cope by populations affected by disasters should not be underestimated. Being the study's results basically coherent with the available literature on the topic, the present study contributed to deepen the knowledge of disasters' impact on the quality of life of the people affected, specially with reference to the influence of foreign aid in the recovery process. Indeed, the study showed that there was a so 
called "greed aspect of the tsunami" linked to the dynamics put into action by the aid and relief work, that can contribute to the perpetuation of poverty trends within such communities hit by disasters.

In this context, it is important to investigate the interrelationships between poverty, disaster risk and livelihoods at the conceptual and application levels, and to demand the required changes in policy, investment and practice from national governments and international relief and development donors. To do so, the issues of the "paradigm shift" from emergency management to disaster risk management need to be addressed, and ways and means of making this a reality should be defined.

At present, the need for an effective disaster riskmanagement system as an integral part of the development process is generally recognised. However, even after such large-scale disasters, the recovery programmes continue to fail to effectively reduce the risk. The present study shows that not everybody is at the same level of risk, not everybody is affected in the same manner by disasters, and not everybody has the same capacity and ability to recover from disasters. Yet the policies that govern reconstruction programmes are hardly ever nuanced enough to respond to these differential vulnerabilities.

Important international declarations, such as the Hyogo Framework for Action 2005-2015 at the World Conference on Disaster Reduction in Kobe, Japan [44], as well as the "Towards a safer Sri Lanka: a roadmap for disaster risk management" published at the national level by the Disaster Management Centre [45], Ministry of Disaster Management of Sri Lanka, with the support of the United Nations

\section{References}

1. Birkmann J (Ed.). Measuring vulnerability to natural hazards: towards disaster-resilient societies. Tokyo, New York, Paris: United Nations University Press; 2006.

2. Ariyabandu M, Bhatti A. Livelihood centered approach to disaster management: a policy framework for south Asia. Colombo: Duryog Nivaran, Practical Action, Rural Development Policy Institute (RDPI); 2006.

3. Chambers R, Conway GR. Sustainable rural livelihoods: practical concepts for the $21^{s t}$ century. Brighton: Institute of Development Studies; 1992 (IDS Discussion Paper 296).

4. Cannon T, Twigg J, Rowell J. Social vulnerability, sustainable livelihoods and disasters. Report to Department for International Development, Conflict and Humanitarian Assistance Department and Sustainable Livelihood Office. London: DFID; 2003.

5. Department of Census and Statistics. Census of building and persons affected by tsunami 2004. Colombo: Department of Census and Statistics; 2005. Available from: www.statistics. gov.lk/Tsunamilindex.htm.

6. Frerks G, Klem B. Tsunami response in Sri Lanka: report on a field visit from 6-20 February 2005. Disaster Studies Wageningen University, Conflict Research Unit Clingendael Institute; 2005.

7. International Centre for Migration and Health. The public health consequences of the tsunami: impact on displaced people. Geneva: International Centre for Migration and Health, 2005.
Development Programme, have the main goal of reducing vulnerability and risk through enhancement of knowledge of physical, social, economic, and environmental vulnerability, which emphasises the need to reduce vulnerability. However, as indicated in Tackling the Tides and Tremors [46], of the Hyogo Framework for Action 2005-2015, we have a sound framework of "what" needs to be done to build a future safer from disasters - there remains the "how" of risk reduction that will be much more challenging.

\section{Acknowledgements}

This project benefited from a dedicated and wide working group. In particular, we wish to thank DrS. Senanayake of the Sri Lankan Ministry of Health, the ISS Project Coordinator Dr R. Ferrelli, and the Project Coordinator in Colombo Ms L. Falchetti. We are particularly grateful to Mr Weerasinghe, Mr Sunil, Mr Sibli, Dr Sumanaweera and Mrs Vathsala, as FG moderators and IDI interviewers, as well as all of the Sinhala and Tamil translators, and especially Mr Palipane, Ms Sepali, Ms Varthani and Mr B. Dhuvarahan. We thank Dr C. Berrie for critical appraisal of the manuscript and E. Fontana for help with the Figures. We are also very grateful to the ISS administrative staff, and in particular to S. Battaglia, S. Stacchini, S. Bocci and P. Gozzi. Finally, special thanks to all of the Sri Lankan people who participated in this research study.

\section{Conflict of interest statement}

There are no potential conflicts of interest or any financial or personal relationships with other people or organizations that could inappropriately bias conduct and findings of this study.

Received on 12 August 2011.

Accepted on 11 April 2012.

8. Government of Sri Lanka. Sri Lanka: post tsunami recovery and reconstruction: progress, challenges, way forward. Joint Report of the Government of Sri Lanka and Development Partners. Colombo: Government of Sri Lanka; 2005.

9. Scheper E, Parakrama A, Patel S. Impact of the tsunami response on local and national capacities. Sri Lanka country report. London: Tsunami Evaluation Coalition; 2006.

10. World Bank. Sri Lanka development forum: the economy, the tsunami and poverty reduction. Poverty Reduction and Economic Management Sector Unit, South Asia Region; 2005.

11. World Health Organization. Moving beyond the tsunami: the WHO story. New Delhi: WHO; 2005.

12. Jayasuriya S, Steele P, Weerakoon D. Post-tsunami recovery: issues and challenges in Sri Lanka. Tokyo: Asian Development Bank Institute: 2006. (ADBI Research Paper Series No.71).

13. Bastian S. The politics of foreign aid in Sri Lanka: promoting markets and supporting peace. Colombo: International Centre for Ethnic Studies; 2007.

14. Istituto Superiore di Sanità. Evaluation of the socio-econom$i c$ and health situation in selected districts affected by the tsunami in Sri Lanka. Project report. Rome: Istituto Superiore di Sanità, 2007.

15. Ritchie J, Spencer L. Qualitative data analysis for applied policy research. In: Bryman A, Burgess RG (Ed.). Analysing Qualitative Data. London: Routledge; 1994. p. 173-94. http://dx.doi.org/10.4324/9780203413081_chapter_9 
16. Raphael D, D'Amico J, Brown I, Renwick R. The quality of life profile: a generic measure of health and well-being. Toronto: Quality of Life Research Unit; 1998.

17. Dynes RR. The concept of role in disaster research. In: Dynes RR, De Marchi B, Pelandra C (Ed.s). Sociology of disasters, contributions of sociology to disaster research. Milano: Franco Angeli; 1987.

18. Rodriguez H, Quarantelli EL, Dynes RR (Ed.). Handbook of disaster research. Series: Handbooks of Sociology and Social Research. USA: Springer; 2006.

19. Furedi F. The changing meaning of disaster. Area 2007;39: 482-9. 19. http://dx.doi.org/10.1111/j.1475-4762.2007.00764.x

20. Chambers R. Vulnerability, coping and policy. Brighton: Institute of Development Studies; 1989. (Institute of Development Studies Bulletin 20:1-7) http://dx.doi.org/10.1111/j.1759-5436.1989.mp20002001.x

21. Carballo M, Heal B, Horbaty G. Impact of the tsunami on psychosocial health and well-being. Int Rev Psychiatry 2006; 18:217-23. http://dx.doi.org/10.1080/09540260600655870

22. Katz CL, Pellegrino L, Pandya A, Ng A., De Lisi LE. Research on psychiatric outcomes and interventions subsequent to disasters: a review of the literature. Psychiatry Res 2002;110:201-17. http://dx.doi.org/10.1016/S0165-1781(02)00110-5

23. Davidson JR, McFarlane AC. The extent and impact of mental health problems after disaster. Journal of Clinical Psychiatry 2006;67:9-14.

24. Carballo M, Heal B, Hernandez M. Psycosocial aspects of the Tsunami. J R Soc Med 2005;98:396-9. http://dx.doi.org/10.1258/jrsm.98.9.396

25. Nikapota A. After the tsunami: a story from Sri Lanka. Int Rev Psychiatry 2006;18:275-9. http://dx.doi.org/10.1080/09540260600658262

26. Somasundaram D. Collective trauma in northern Sri Lanka: a qualitative psychosocial-ecological study. Int J Ment Health Syst 2007;1:5. http://dx.doi.org/10.1186/1752-4458-1-5

27. Agampodi TC, Agampodi SB, Fonseka P. Prevalence of mental health problems in adolescent schoolchildren in Galle District, Sri Lanka: eight months after tsunami. Asia Pac J Public Health 2011;23(4):588-600. http://dx.doi.org/10.1177/1010539509349866

28. Berger R, Gelkopf M. School-based intervention for the treatment of tsunami-related distress in children: a quasi-randomized controlled trial. Can J Psychiatry 2009;78:364-71. http://dx.doi.org/10.1159/000235976

29. Catani C, Kohiladevy M, Ruf M, Schauer E, Elbert T, Neuner F. Treating children traumatized by war and tsunami: a comparison between exposure therapy and meditation-relaxation in north-east Sri Lanka. BMC Psychiatry 2009;9:22. http://dx.doi.org/10.1186/1471-244X-9-22

30. De Silva P. The tsunami and its aftermath in Sri Lanka: explorations of a Buddhist perspective. Int Rev Psychiatry 2006; $18: 281-7$. http://dx.doi.org/10.1080/09540260600658270

31. Poston A. Lessons from a microfinance recapitalisation programme. Disasters 2010;34:328-36. http://dx.doi.org/10.1111/j.1467-7717.2009.01131.x

32. Boano C. Housing anxiety and multiple geographies in posttsunami Sri Lanka. Disasters 2009;33:762-85. http://dx.doi.org/10.1111/j.1467-7717.2009.01108.x
33. Lee AC. Local perspectives on humanitarian aid in Sri Lanka after the tsunami. Public Health 2008;122:1410-7. http://dx.doi.org/10.1016/j.puhe.2008.06.004

34. Amarasiri de Silva MW. Ethnicity, politics and inequality: post-tsunami humanitarian aid delivery in Ampara District, Sri Lanka. Disasters 2009;33:253-73. http://dx.doi.org/10.1111/j.1467-7717.2008.01073.x

35. Turner A, Pathirana S, Daley A, Gill PS. Sri Lankan tsunami refugees: a cross-sectional study of the relationships between housing conditions and self-reported health. $B M C$ Int Health Hum Rights 2009;9:16. http://dx.doi.org/10.1186/1472-698X-9-16

36. Silva T. Perceptions of vulnerability and coping in conflictaffected populations: interplay among poverty, ethnicity and conflict in dry zone Sri Lanka. In: Poverty issues in Sri Lanka; towards new empirical evidence. Colombo: Centre for Poverty Analysis, Improving Capacities for Poverty Research Programme and Sri Lankan Association for the Advancement of Science, 2003. p. 95-125.

37. De Silva DAM., Yamao M. Effects of the tsunami on fisheries and coastal livelihood: a case study of tsunami-ravaged southern Sri Lanka. Disasters 2007;31:386-404. http://dx.doi.org/10.1111/j.1467-7717.2007.01015.x

38. Birkmann J, Fernando N. Measuring revealed and emergent vulnerabilities of coastal communities to tsunami in Sri Lanka. Disasters 2008;32:82-105.

http://dx.doi.org/10.1111/j.1467-7717.2007.01028.x

39. United Nations Educational, Scientific and Cultural Organization, Intergovernmental Oceanographic Commission. Assessment of capacity building requirements for an effective and durable tsunami warning and mitigation system in the Indian Ocean: consolidated report for countries affected by the 26 December 2004 tsunami. Paris: UNESCO-IOC; 2005. (Information document No. 1219).

40. Kurita T. Capacity Building Project in Sri Lanka. Report at the United Nation University Institute of Environment and Human Security workshop on Vulnerability Assessment and Early Warning. Colombo, UNU-EHS; 2006.

41. Bird D, Dominey-Howes D. Testing the use of a "questionnaire survey instrument" to investigate public perceptions of tsunami hazard and risk. Natural Hazards 2008;45:99-122. http://dx.doi.org/10.1007/s11069-007-9172-8

42. Heijmans A. Vulnerability: a matter of perception. London: Benfield Greog Hazard Research Centre; 2001 (Disaster Management Working Paper 4/2001).

43. De Mel S, McKenzie D, Woodruff C. Mental health recovery and economic recovery after the tsunami: high-frequency longitudinal evidence from Sri Lankan small business owners. Soc Sci Med 2008;66:582-95. http://dx.doi.org/10.1016/j.socscimed.2007.10.006

44. United Nations. Building the resilience of nations and communities to disasters. World Conference on Disaster Reduction, Hyogo Framework for Action 2005-2015. Kobe, Hyogo, Japan, 2005.

45. Disaster Management Centre. Towards a safer Sri Lanka: a roadmap for disaster risk management. Colombo: Ministry of Disaster Management of Sri Lanka, United Nations Development Programme; 2005.

46. Wisner B, Platt L, Bhatti A. Tackling the tides and tremors: South Asia disaster report 2005. Rawalpindi, Pakistan: Duryog Nivaran Secretariat and Practical Action- South Asia Programme. Colombo, Sri Lanka, 2006. 